\title{
Cervical Spine Involvement: A Rare Manifestation of Reiter's Syndrome
}

\author{
Khodakaram Rastegar ${ }^{1}$, Hossein Ghalaenovi ${ }^{*},{ }^{1}$, Ali Babashahi ${ }^{1}$, Nasrin Shayanfar ${ }^{2}$, \\ Mohammad Jafari ${ }^{3}$, Mehrdad Jalalian ${ }^{4}$, Arash Fattahi ${ }^{3}$
}

\author{
${ }^{I}$ Neurosurgery ward of Rasool-e-Akram Hospital Complex, Department of Neurosurgery, Iran University of Medical \\ Science, Tehran, Iran \\ ${ }^{2}$ Pathology ward of Rasool-e-Akram Hospital Complex, Department of Pathology, Iran University of Medical Science, \\ Tehran, Iran \\ ${ }^{3}$ Medical Doctor, Resident of Neurosurgery, Neurosurgery Ward of Rasool-e-Akram Hospital Complex, Department of \\ Neurosurgery, Iran University of Medical Science, Tehran, Iran \\ ${ }^{4}$ Editor In-Chief, Electronic Physician, Mashhad, Iran
}

\begin{abstract}
Spine involvement is less common in Reiter's syndrome than in other seronegative spondyloarthropathies. Also, cervical spine involvement rarely occurs in Reiter's syndrome and other spondyloarthropathies. This paper reports a rare case of Reiter's syndrome in which there was cervical spine involvement that presented clinically as an atlanto-axial rotatory subluxation. Reiter's Syndrome (RS) is one of the most common types of seronegative spondyloarthropathies (SSAs) that presents clinically with a triad of symptoms, i.e., conjunctivitis, urethritis, and arthritis. This case highlighted the importance of radiographs of the lateral cervical spine and dynamic cervical imaging for all patients who have Reiter's syndrome with cervical spine symptoms to ensure that this dangerous abnormality is not overlooked.
\end{abstract}

Keywords: Atlanto-axial rotatory subluxation, Reiter's syndrome, spondyloarthropathy.

\section{INTRODUCTION}

Reiter's Syndrome (RS) is one of the most common types of seronegative spondyloarthropathies (SSAs), and it presents clinically with a triad of symptoms, i.e., conjunctivitis, urethritis, and arthritis [1-3]. The term 'reactive arthritis' applies to all cases of infection-induced arthritis, such as gastrointestinal and genitourinary infections in which the organisms are located outside the joints, but the term RS, which is rare, should be reserved for the classical triad [4-7]. This syndrome is more prevalent in young adults, and the age at which the onset of symptoms occurs is 23-27 $[1,8,9]$. Among patients who have RS, the male-to-female ratio is 5:1 [10]. Involvement of the spine in RS is less common than in other SSAs. The involvement of the cervical spine in this syndrome and in other spondyloarthropathies (SAPs) is a rare clinical presentation; fewer than $6 \%$ of patients with Reiter's syndrome revealed cervical radiographic abnormalities [11-13]. It is clear that this condition is dangerous due to the potential for subsequent, adverse consequences, and it is very important to be aware that RS can involve the cervical spine as atlanto-axial rotatory sublaxation. Since overlooking the instability of the upper cervical spine can lead to lethal complications, we decided to present this patient as a case report in order to

*Address correspondence to this author at the Neurosurgery ward of Rasoole-Akram Hospital Complex, Department of Neurosurgery, Iran University of Medical Sciences, Tehran, Iran; Tel: +98.9124623806;

Fax: +98.2164352228; E-mail: hghalaenovi@yahoo.com direct more attention to this condition. In this article, we present a case of RS with atlanto-axial rotatory subluxation (AARS) that was treated surgically in the Department of Neurosurgery at the Iran University of Medical Sciences in Tehran, Iran.

\section{CASE PRESENTATION}

\subsection{Clinical Presentation}

The patient was a 20 -year-old male with a 10 -month history of pain in the cervical, sacroiliac, and peripheral joints accompanied by a skin rash. He had generalized weakness, anorexia, and intermittent, low-grade fever. The pain in the joints began in the sacroiliac and then extended to the peripheral and upper cervical spine. Also, he had pain in the upper cervical spine, but other parts of his spine were asymptomatic. He had morning stiffness for more than three hours, and his symptoms were worse at night and when he was resting. All of his symptoms progressed during the 10month period, and he was unable to work. There was no sphincter disturbance.

The patient's head was tilted mildly to right and flexed. The range of motion of the peripheral joints was decreased, and movement was accompanied by tenderness and pain in most of the joints. The muscle strength of the upper extremities was unaffected, and there was no neurological deficit; however, the lower extremities had mild paraparesis (muscle strength score of 4 , based on a five-point scale, in both distal and proximal of the lower limbs) with severe pain 
associated with all movements (passive and active). There was no hyperreflexia or signs of upper motor neuron issues. Scaling erythematous skin lesions was detected on the extensor surfaces of the extremities (keratoderma blennorrhagica). The patient indicated that he had short-term, bilateral red eye and dysuria before his admission to the hospital. Sausage-form digits (dactylitis) were observed on both hands. He had nail involvement in the form of nail hyperkeratosis and onycholysis. Also, he had balanitis circinata (also known as circinate balanitis) that was manifested as annular dermatitis of the glans penis.

\subsection{Past History}

The patient had a history of unsafe sexual contact with subsequent bloody and mucopurulent discharge from the penis and other symptoms of sexually-transmitted disease. The familial history of this patient was negative.

\subsection{Laboratory Findings}

He underwent skin lesion biopsy that revealed psoriaform tissue reaction with intra-epidermal pustule formation, associated with keratoderma blennorrhagicum (Fig. 1). There were some significant abnormal findings in his laboratory data, such as leukocytosis, thrombocytosis, elevated erythrocyte sedimentation rate (110) and C-reactive protein [24], urine pyorrhea, and positive HLA-B27. He had negative rheumatoid factor (RF) testing.

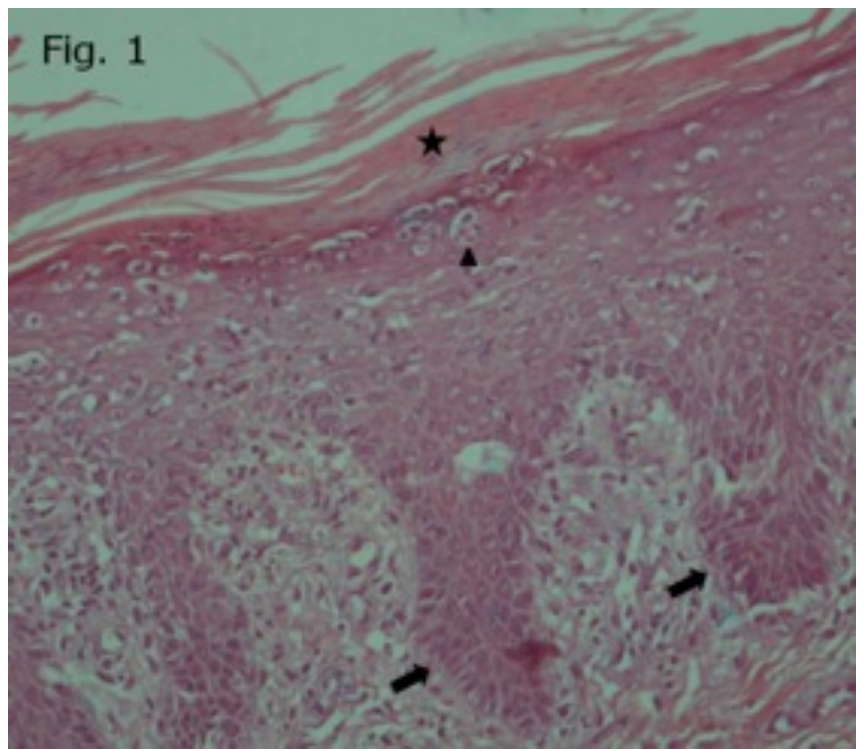

Fig. (1). Pathology revealed psoriaform tissue reaction with intraepidermal pustule formation, associated with keratoderma blennorrhagicum. Parakeratosis confluent (asterisk), spongiform pustules and micro-abscess (arrow heads), and Regular (psoriaform) acanthosis (arrows) are shown in the image.

\subsection{Imaging}

The pelvic X-ray and MRI indicated the presence of bilateral sacroiliitis (Fig. 2a, b). The cervical spine X-ray showed that there was a $27 \mathrm{~mm}$ anterior displacement of the cranio-atlantal complex on the axis (Fig. 3a). The MRI of the cervical spine with and without contrast indicated the presence of tearing of the transverse ligament accompanied by posterior displacement of the odontoid process (Fig. 3b) and cervical cord compression from the left and $\mathrm{C} 1$ rotation to the right (Figs. 3c, d). The anterior unilateral displacement of $\mathrm{C} 1$ on $\mathrm{C} 2$ was greater than $5 \mathrm{~mm}$. Thus, the patient's AARS was grade 3 based on Fielding grading [14] and unilateral anterior based on the White and Panjabi classification [15]. Dynamic imaging showed that there was significant angulation in the atlantoaxial junction (Fig. 4a, b).

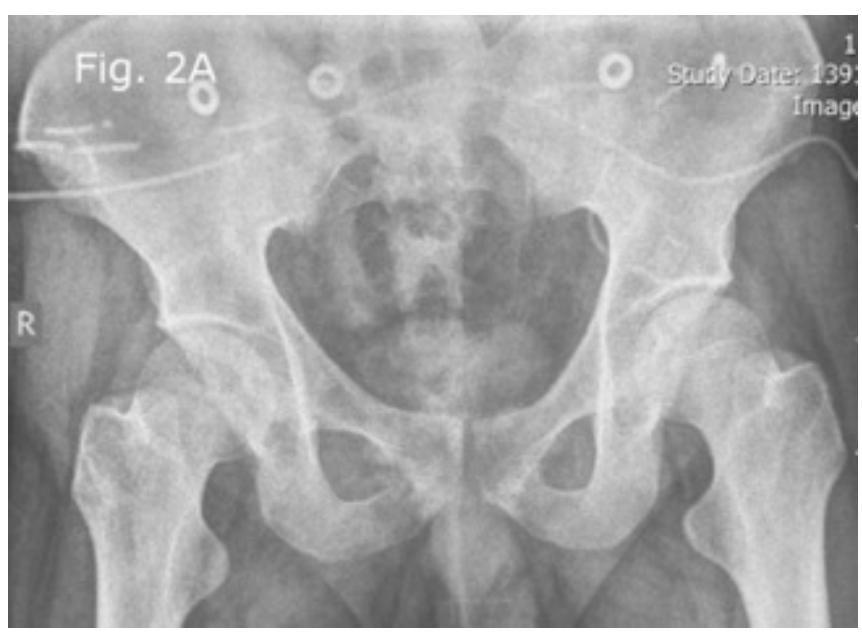

Fig. (2a). Pelvic radiograph showing sacroiliitis.

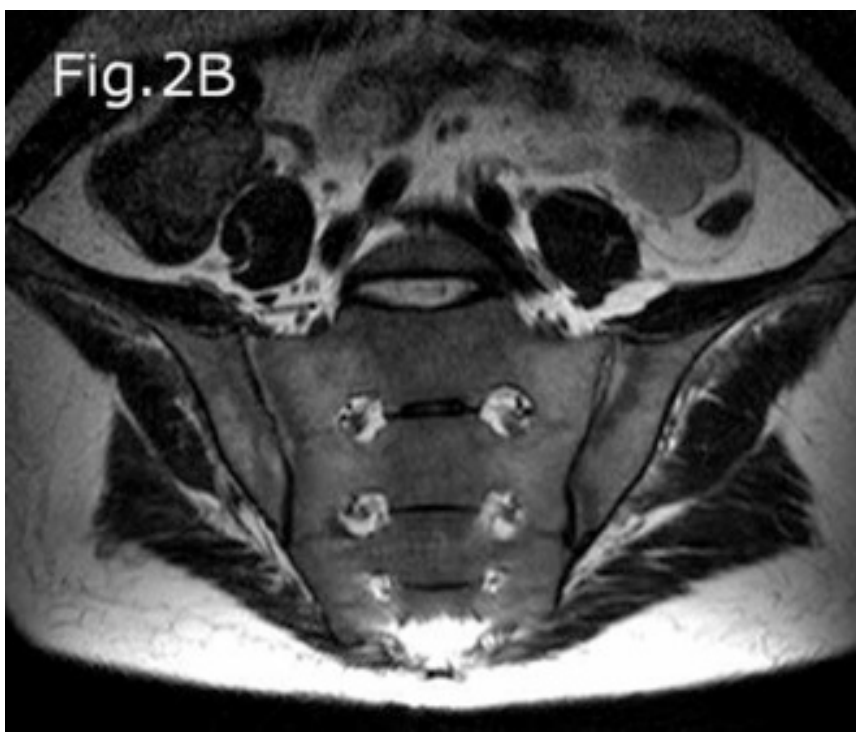

Fig. (2b). MRI of the SI joint, T2 weighted sequence shows bilateral sacroiliitis.

\subsection{Surgical Intervention}

The patient underwent five pounds of traction with Gardner-Wells tongs in a neutral position. Because the dislocation of the upper cervical spine was reducible with traction (Fig. 5a-c), we decided to perform open reduction surgery from the posterior, based on the diagnosis of AARS. Thus, before the patient was anesthetized, he was intubated and placed in a prone position with five pounds traction; the forces on all four limbs were rechecked, and he underwent generalized anesthesia. The intraoperative reduction was 


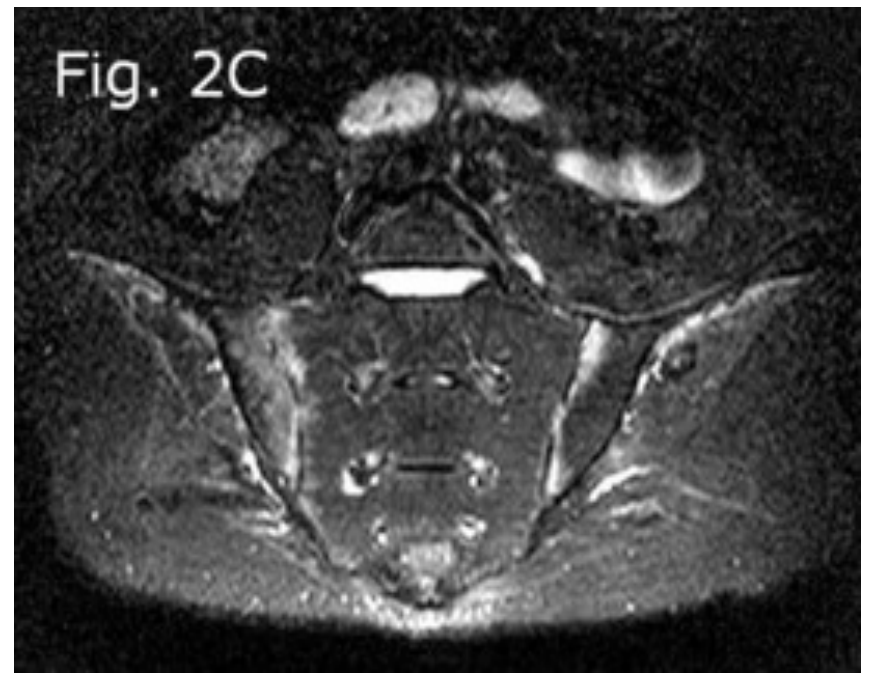

Fig. (2c). MRI of the SI joint, STIR sequence shows active inflammation in both SI joints.

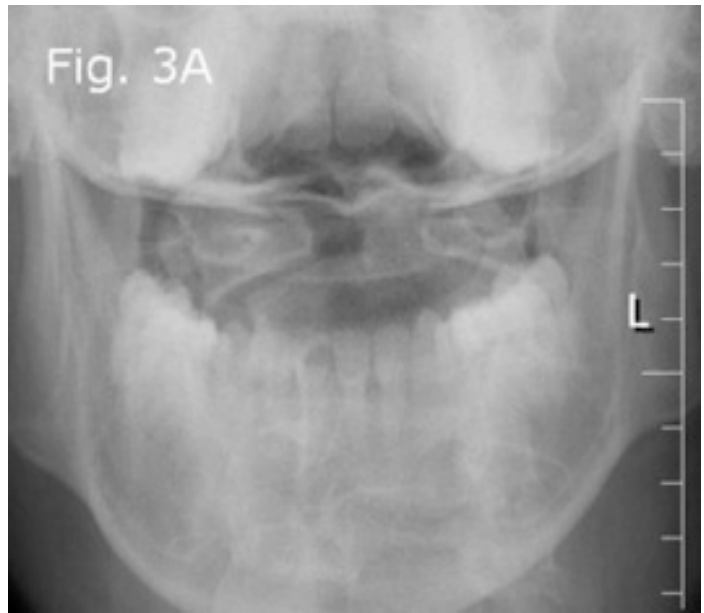

Fig. (3a). Pre-operative odontoid view radiograph: Bilateral C1-C2 joint space and distance between odontoid process with medial border of $\mathrm{C} 1$ lateral mass, on both sides, appears asymmetric.

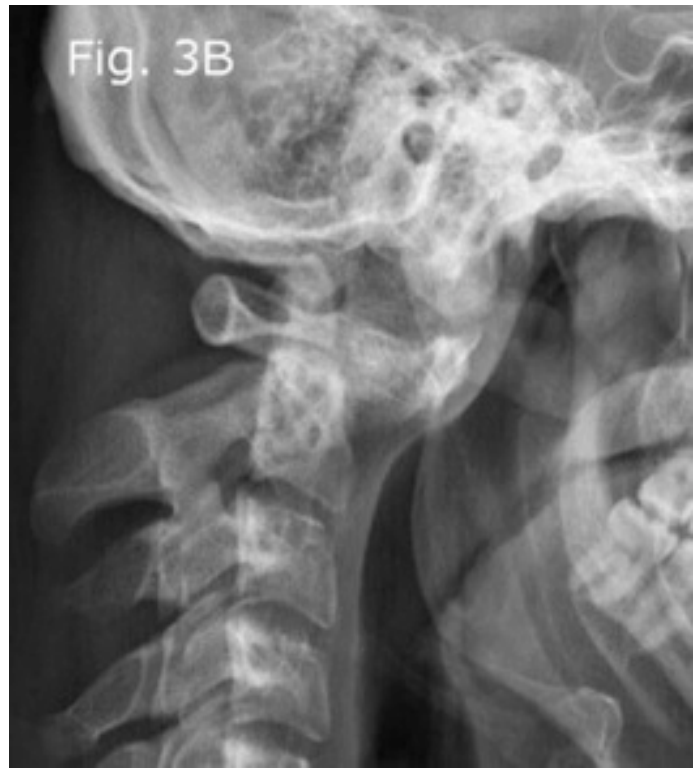

Fig. (3b). Pre-operative lateral radiograph showing significant cranio-atlantal anterior dislocation and angulation on the axis.

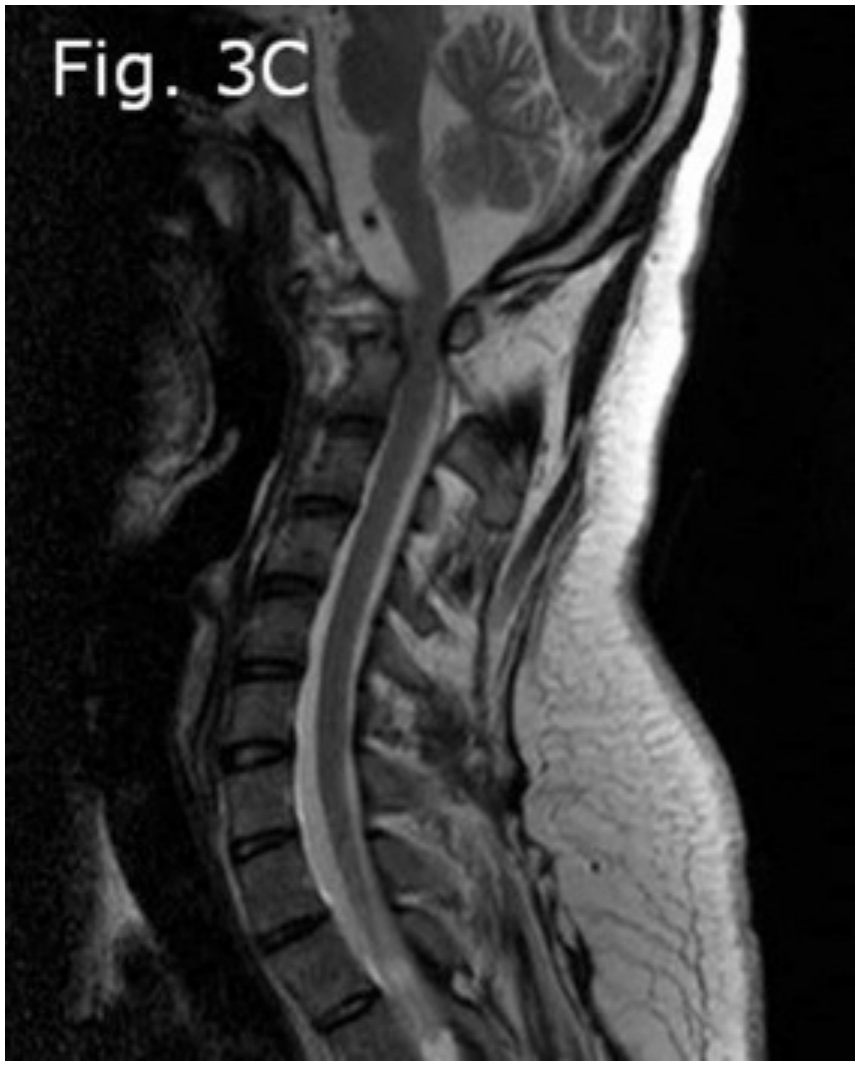

Fig. (3c). Pre-operative cervical MRI T2-weighted (sagittal view) showing significant reduction of the anterior-posterior diameter of the intra-canal space.

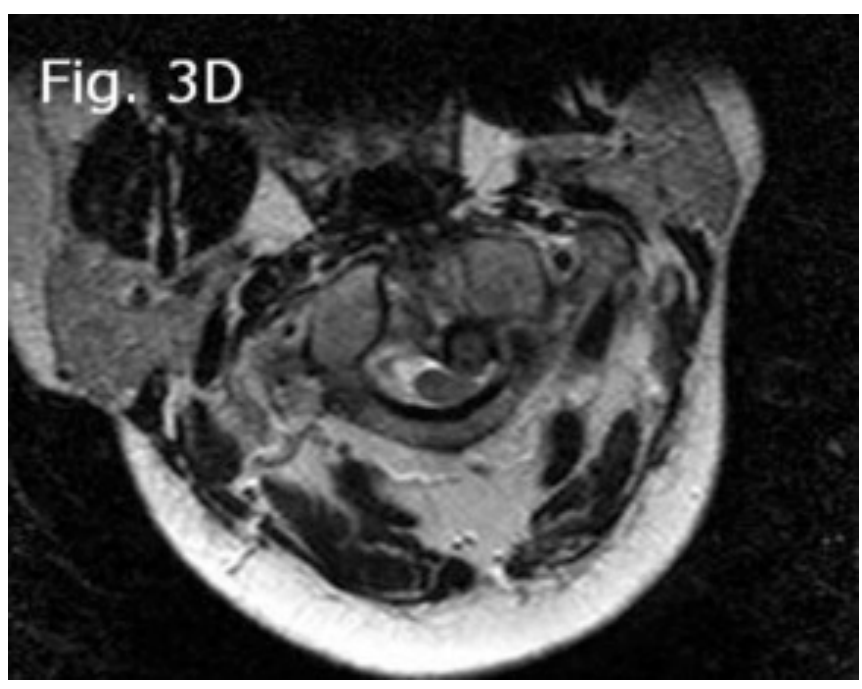

Fig. (3d). Preoperative cervical MRI T2-weighted (axial view) showing left and posterior displacement of dens and $\mathrm{C} 1$ rotation to right.

performed using a fluoroscopic guide. Then, $\mathrm{C} 1$ bilateral laminar hooks and $\mathrm{C} 2$ bilateral pedicular screws were placed and connected with rods; also, an autograft and allograft bone for fusion was added. Control imaging was obtained intraoperatively.

\subsection{Follow-Up with the Patient}

Immediately after the operation and at the three-month follow-up examination, the patient had no neurological 
deficits, no instability or canal compromise in imaging (Fig. 6a-c), and no cervical manifestation, except limited cervical rotation.

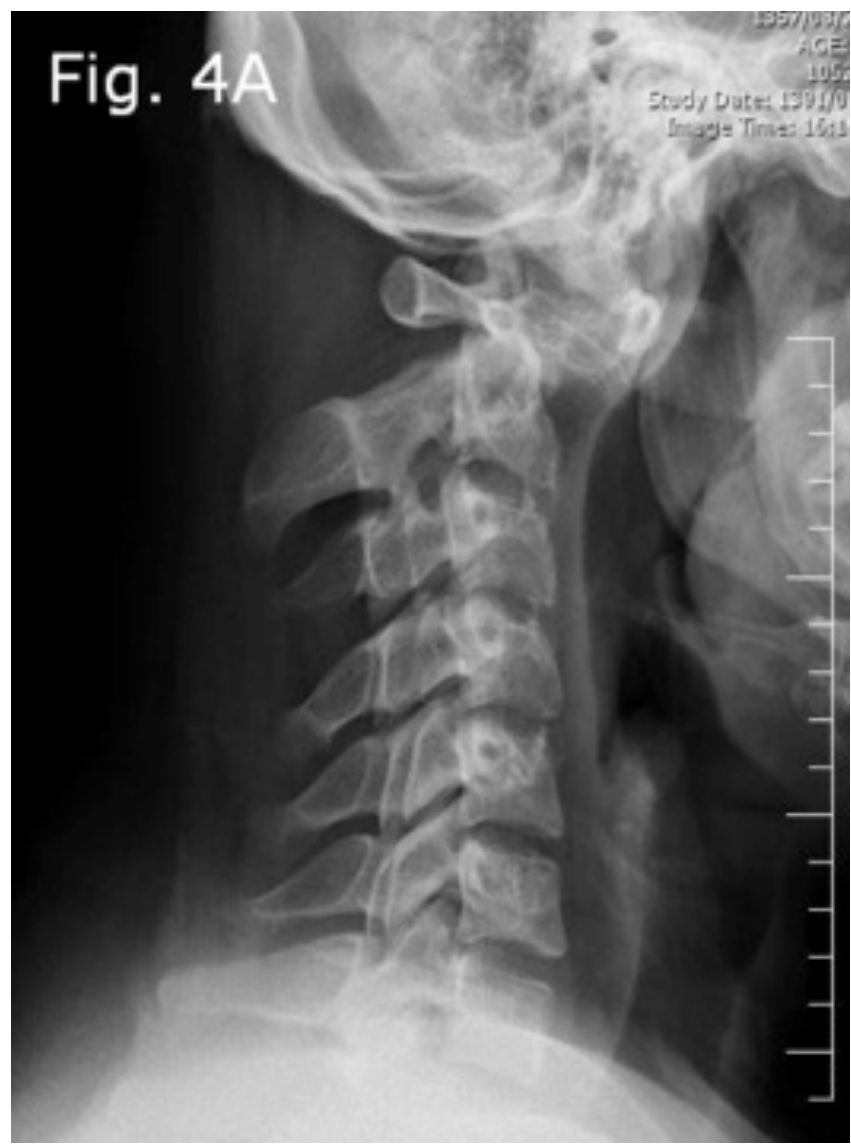

Fig. (4a). Dynamic imaging radiograph with significant angulation in the atlanto-axial junction on flexion view.

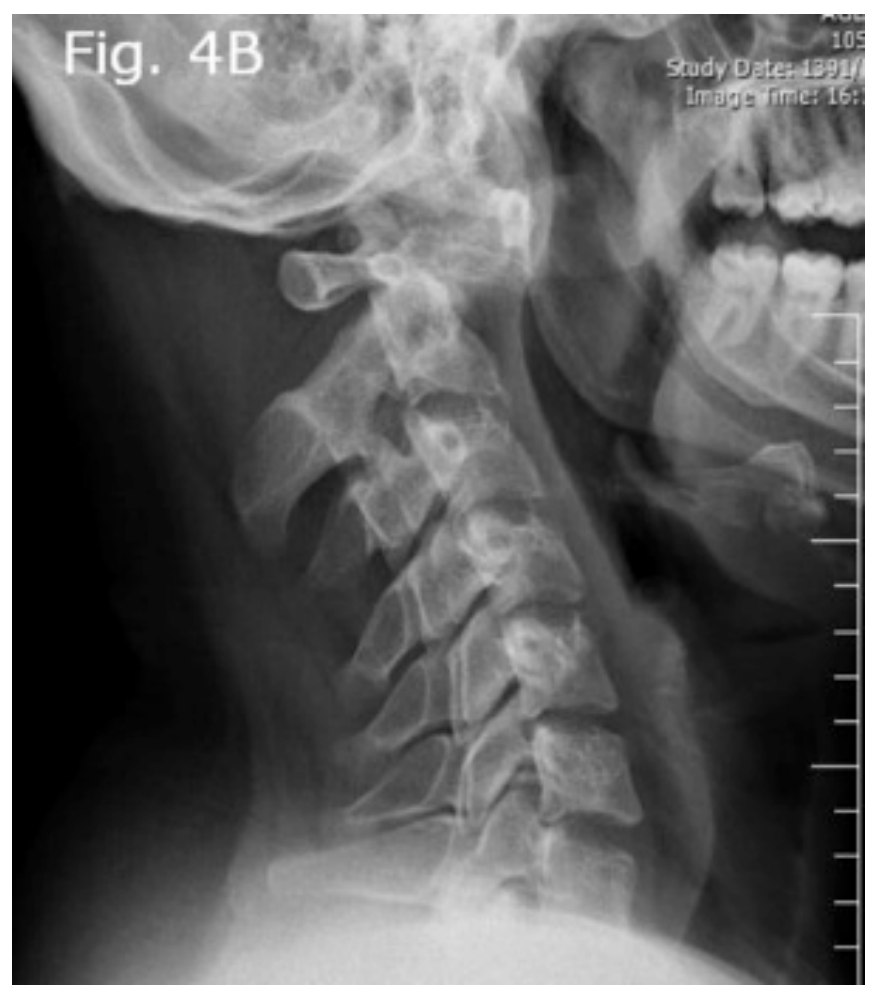

Fig. (4b). Dynamic imaging radiograph, extension view.

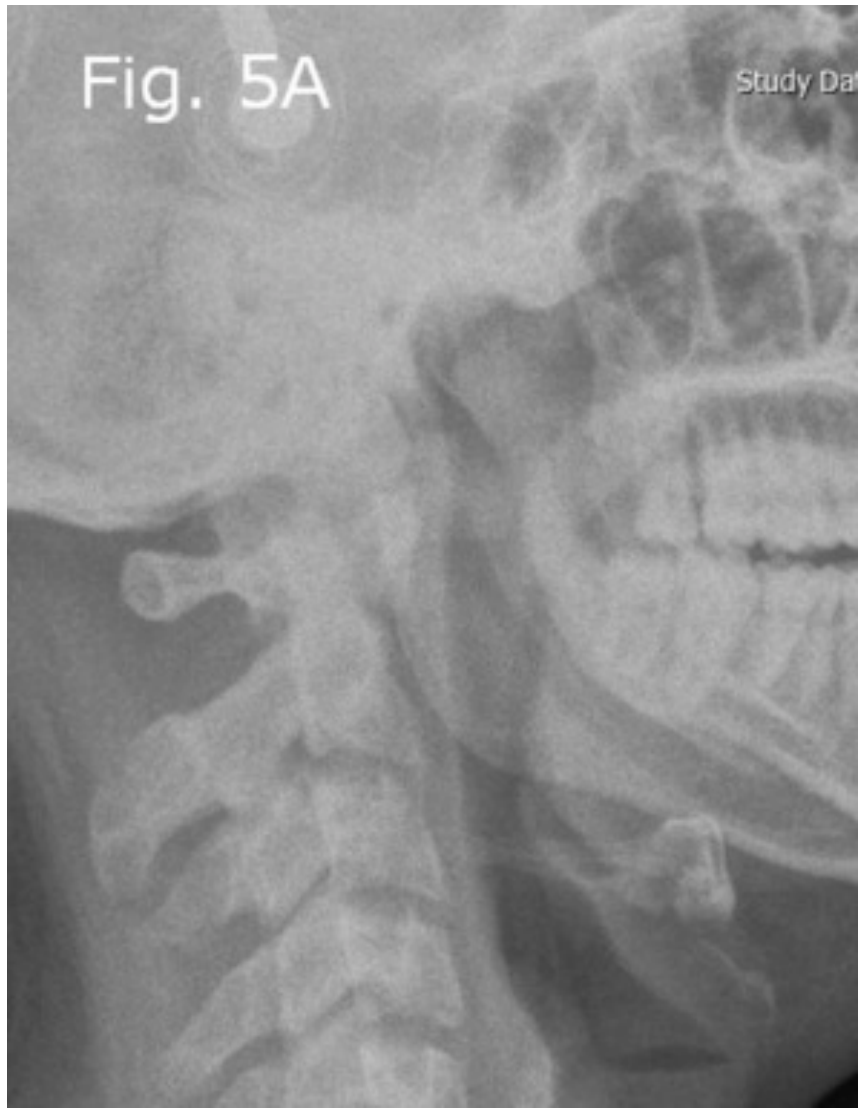

Fig. (5a). Cervical lateral radiograph obtained after traction with five-lb Gardner-Wells tongs: Post-traction PADI increased to 20 $\mathrm{mm}$.

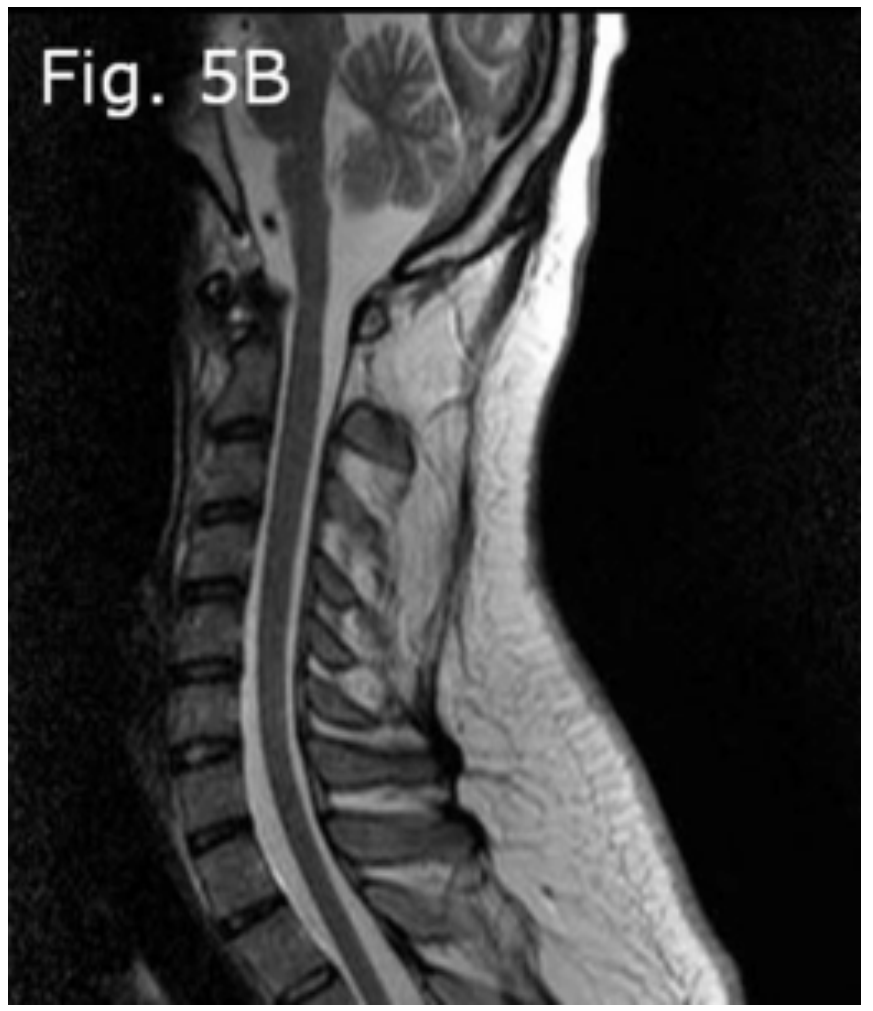

Fig. (5b). Cervical MRI obtained after traction with five-lb Gardner-Wells tongs (sagittal view): The reducibility of this pathology is shown. 


\section{Fig. 5C}

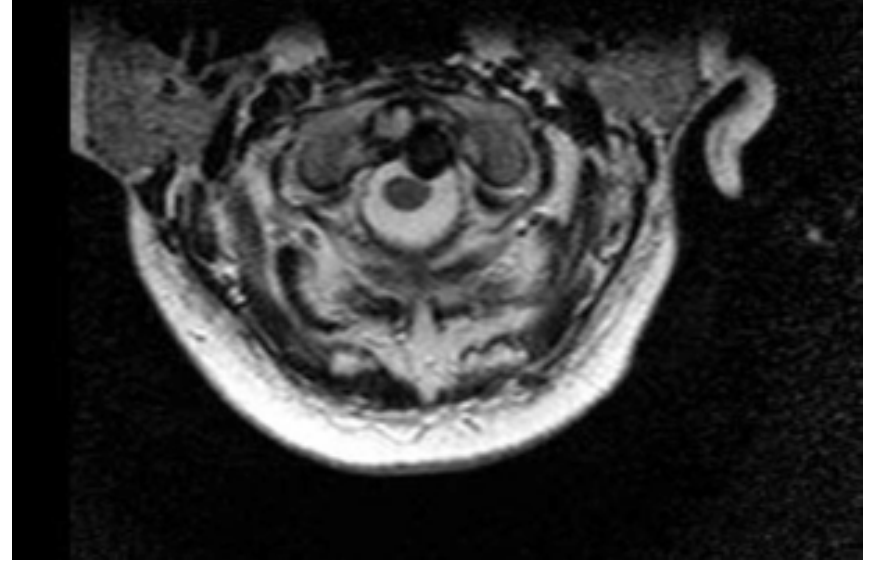

Fig. (5c). Cervical MRI (axial view): Shows the decreased compression of the cord.

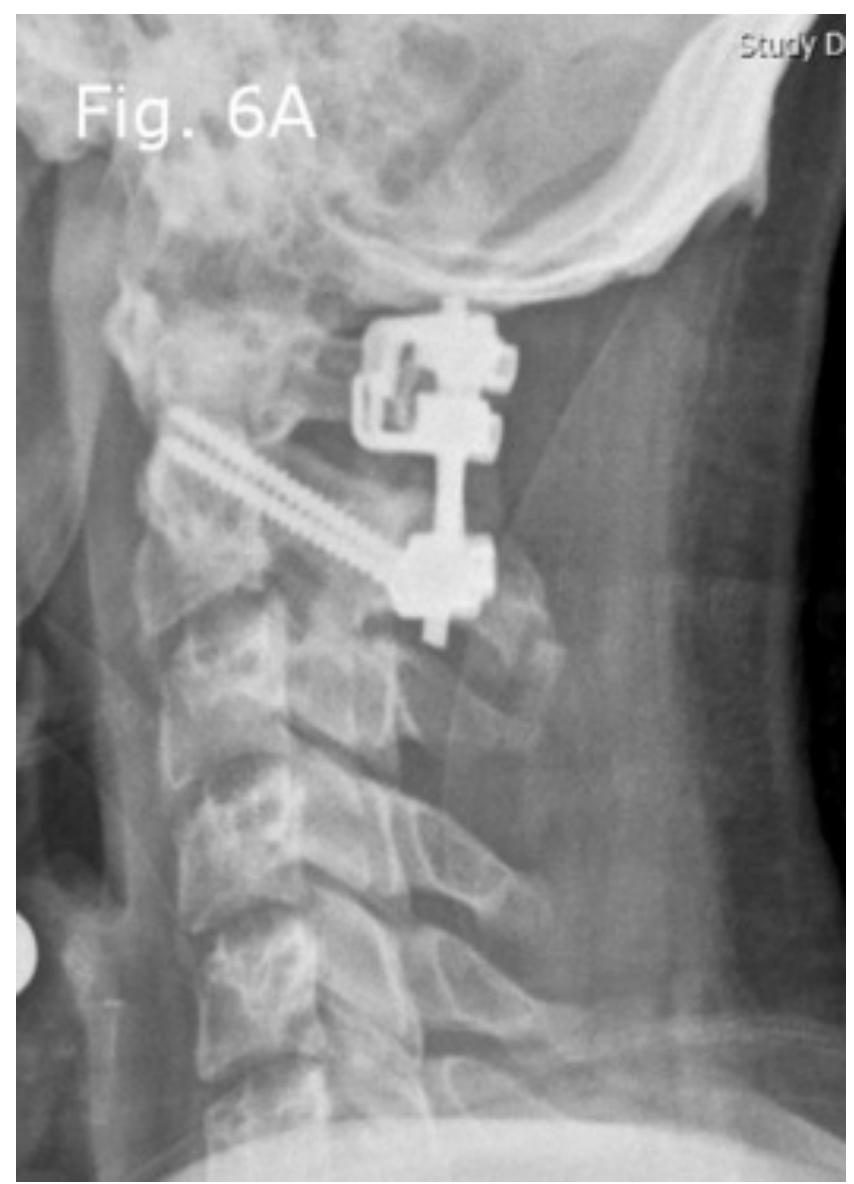

Fig. (6a). Post-operative lateral radiograph. C1 bilateral laminar hooks and $\mathrm{C} 2$ bilateral pedicular screws were placed and connected with rods, as well with autograft and allograft bone for fusion.

\section{DISCUSSION}

The SSAs are a group of inflammatory diseases that have presented with inflammatory back pain, enthesopathy and peripheral arthritis [16]. This group of diseases includes

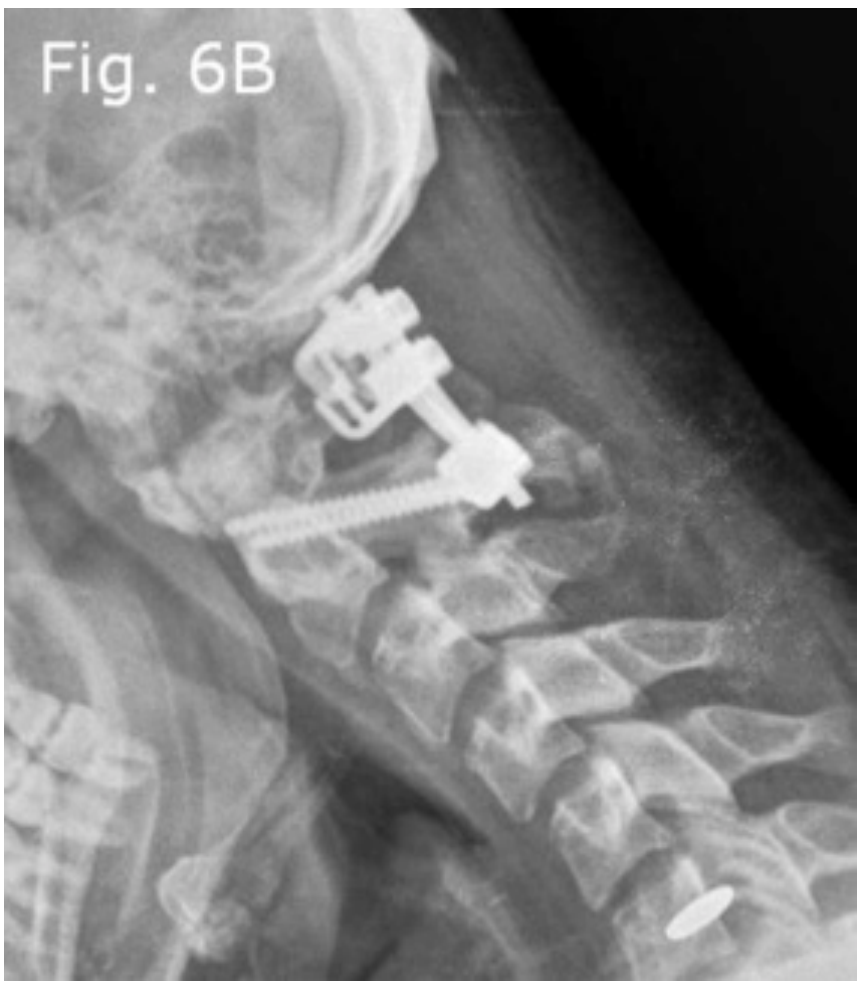

Fig. (6b). Post-operative lateral flexion radiograph: Shows no displacement of the atlas on the axis.

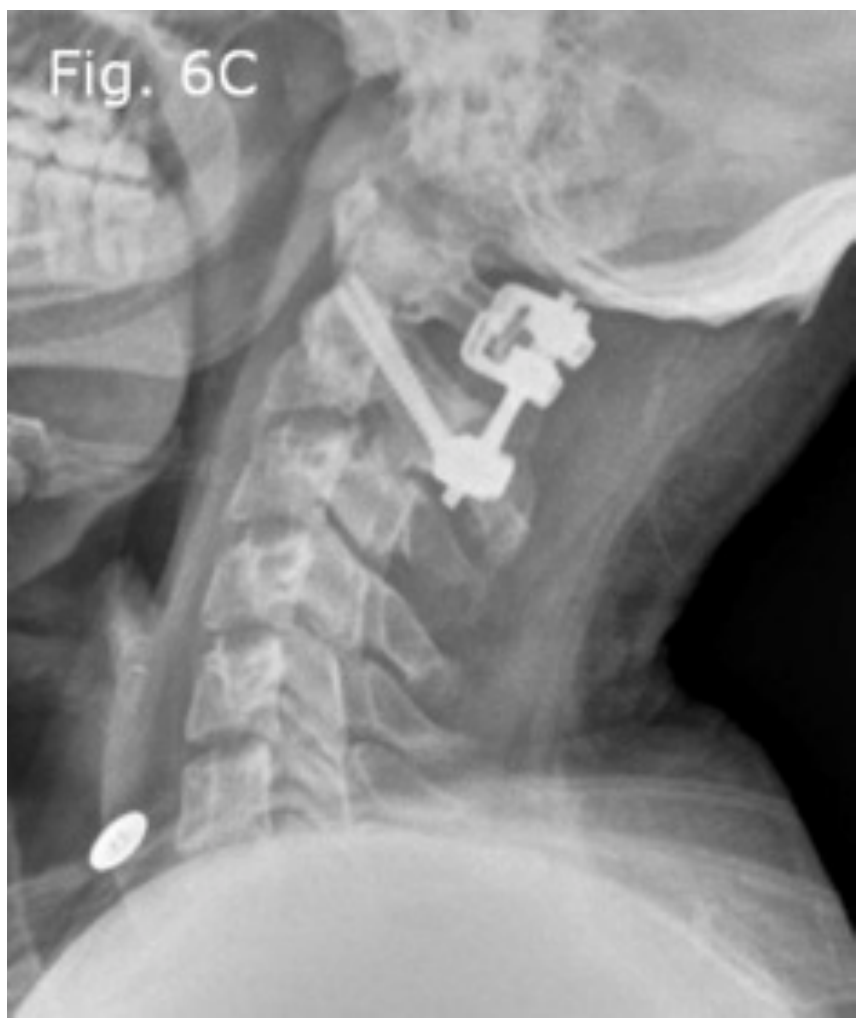

Fig. (6c). Post-operative lateral extension radiograph.

ankylosing spondylitis (AS), psoriatic arthritis (PA), Reiter's Syndrome/Reactive Arthritis (RS), and the arthritis associated with inflammatory bowel diseases (IBDs). The patients with AS and IBDs have more prevalent spinal disease, as symmetrical and continuous fusion, but dactylitis 
and dermatologic manifestations are uncommon in these subtypes. The PA is associated with psoriasis that often precedes the arthritis symptoms, sometimes by many years; however, our patient had not any symptoms of psoriasis or inflammatory bowel disease, formerly. In other hand, keratoderma blennorrhgica is a characteristic skin lesion in RS that was found in our patient [17]. Reactive arthritis is a systematic reaction of the body's immune system to infection in another site in the body, and these infections commonly are urogenital or gastrointestinal infections. Our patient had a history of unsafe sexual contact. RS is a form of reactive arthritis that can develop at any age, but it occurs most often in young men $[3,8,9]$. The typical, classic, triad manifestation in the course of this syndrome is observed in only $55 \%$ of patients [1]. Our patient had no symptoms of uveitis during the course of disease, but he did have shortterm conjunctivitis.

Concerning the association SSAs with positive tests for HLA-B27, most people who have a positive test do not have these diseases, and some patients who do have one of the SSA diseases have negative tests for HLA-B27. Thus, this test cannot exclude or confirm these diseases [18]. But the patients with positive HLA-B27 have more severe and acute disease [19]. HLA-B27 is associated strongly with RS (60$85 \%$ ), but AS has a $90 \%$ association [20, 21]. For our patient, HLA-B27 was positive, and other acute-phase reactants were elevated. Based on criteria established by the European Spondyloarthropathy Study Group (ESSG) [22], our patient had morning stiffness longer than 30 minutes; inflammatory low-back pain; the onset of symptoms prior to age 40; improvement of pain with exercise; involvement of the peripheral joints, predominantly in the lower limbs; reduction in the range of motion in both active and passive movement; and the symptoms worse with rest. The patient had no positive familial history and no uveitis.

The AARS is referred to the increased rotational instability of the $\mathrm{C} 1-\mathrm{C} 2$ joint due to traumatic injury or, less common, ligamentous laxity. Ligamentous laxity can occur with many pathological conditions, such as congenital causes or acquired inflammatory involvement of the transverse ligament. This condition is more prevalent in children, but its overall incidence is very low [23]. A mean force of $84 \mathrm{~kg}$ is required to rupture the transverse ligament and, at least, 3-5 $\mathrm{mm}$ of anterior dislocation of $\mathrm{C} 1$ on $\mathrm{C} 2$ [24]. Thus, a serious, traumatic injury or transverse ligament weakness is necessary to produce this abnormal condition. Patients with AARS have painful cervical motions and torticollis [13, 25]. The prevalence of AARS in association with RS is rare, and this event is more unusual than it is with other SSAs [12]. It is clear that this condition is dangerous due to its potential subsequent consequences, if this condition is overlooked, it can result in hazardous events, even sudden death.

In the medical treatment of peripheral arthritis in these patients, disease-modifying, anti-rheumatic drugs (DMARDs), such as methotrexate and anti-TNFs including infliximab, are recommended [26, 27]; however, when there is involvement of the axial spine, anti-TNF therapy has proven to be more effective than the use of DMARDs [28]. The selection of surgical therapy or conservative therapy for RS atlanto-axial involvement depends on the presence of intractable cervical pain, significant dislocation of the atlas on the axis, decreased space around the cord in the craniocervical junction, significant instability indicated by dynamic imaging, transverse ligament tearing shown by an MRI, nonreducible dislocation with traction, and neurological deficit in physical examination [13, 25, 29-31]. If the posterior atlanto-dental interval (PADI) is less than $14 \mathrm{~mm}$ on the Xray of the lateral cervical flexion (9 $\mathrm{mm}$ in our patient) or the space around the cord is less than $13 \mathrm{~mm}$ based on MRI (8 $\mathrm{mm}$ in our patient), arthrodesis is recommend even if the patient is asymptomatic (prophylactic surgery) [30]. Our patient did not have transverse ligament tearing or any neurological deficits, and the abnormality was reducible with traction. However, because of its very low PADI and the narrow space around the cord, we decided to repair his C1$\mathrm{C} 2$ complex with posterior instrumentation and fusion.

Although, RS is an inflammatory disease with rare cervical involvement, such as atlanto-axial subluxation, keep in mind that this association, as one of conditions that can be manifested with cervical pain and, in some cases, with torticoli, can ensure that we do not overlook any such involvement. Thus, lateral radiographs of the cervical spine and dynamic cervical imaging are recommended for all patients with RS who have symptoms associated with the cervical spine [32].

\section{CONCLUSION}

We presented a case of RS accompanied with atlantoaxial rotatory subluxation, which occurs rarely, thus emphasizing the importance of this case. Again, this rare condition can be lethal if it is overlooked and not treated appropriately. This case reminds us to obtain lateral cervical spine radiographs and dynamic cervical $\mathrm{X}$-rays for all patients with RS and symptoms that are associated with the cervical spine.

\section{CONFLICT OF INTEREST}

The authors confirm that this article content has no conflict of interest.

\section{ACKNOWLEDGEMENTS}

The authors gratefully thank Dr. Maziar Azar (Head of Department of Neurosurgery, Iran University of Medical Science) for his scientific support for this study.

\section{REFERENCES}

[1] Asauliuk IK, Zamkovaia NV, Skripets A. [Reiter disease: clinical manifestations and diagnostic criteria]. Lik Sprava 2001; 3; 94-9. Pubmed PMID: 11560042.

[2] Toivanen A. Managing reactive arthritis. Rheumatology (Oxford) 2000; 39(2): 117-9.

[3] Wu IB, Schwartz RA. Reiter's syndrome: the classic triad and more. J Am Acad Dermatol 2008; 59(1): 113-21.

[4] Keat A. Reiter's syndrome and reactive arthritis in perspective. N Engl J Med 1983; 309(26): 1606-15.

[5] Michet CJ, Machado EB, Ballard DJ, McKenna CH. Epidemiology of Reiter's syndrome in Rochester, Minnesota: 1950-1980. Arthritis Rheum 1988; 31(3): 428-31.

[6] Iliopoulos A, Karras D, Ioakimidis D, et al. Change in the epidemiology of Reiter's syndrome (reactive arthritis) in the postAIDS era? An analysis of cases appearing in the Greek Army. J Rheumatol 1995; 22(2): 252-4. 
[7] Kim SK, An JY, Park MS, Kim BJ. A Case Report of Reiter's Syndrome with Progressive Myelopathy. J Clin Neurol 2007; 3(4): 215-8.

[8] Deesomchok U, Tumrasvin T. Clinical comparison of patients with ankylosing spondylitis, Reiter's syndrome and psoriatic arthritis. J Med Assoc Thai 1993; 76(2): 61-70.

[9] Butler MJ, Russell AS, Percy JS, Lentle BC. A follow-up study of 48 patients with Reiter's syndrome. Am J Med 1979; 67(5): 808-10.

[10] Miller KE. Diagnosis and treatment of Chlamydia trachomatis infection. Am Fam Physician. 2006; 73(8): 1411-6.

[11] Fox B, Sahuquillo J, Poca MA, Huguet P, Lience E. Reactive arthritis with a severe lesion of the cervical spine. Br J Rheumatol 1997; 36(1): 126-9.

[12] Melsom RD, Benjamin JC, Barnes CG. Spontaneous atlantoaxial subluxation: an unusual presenting manifestation of Reiter's syndrome. Ann Rheum Dis 1989; 48(2); 170-2.

[13] Koopman WJ, Boulware DW, Heudebert GR. Clinical Primer of Rheumatology. Illustrated ed. Philadelphia: Lippincott Williams \& Wilkins; 2003

[14] Fielding JW, Hawkins RJ. Atlanto-axial rotatory fixation (Fixed rotatory subluxation of the atlanto-axial joint). J Bone Joint Surg Am1977; 59(1): 37-44.

[15] White AA, Panjabi MM. Clinical biomechanics of the spine. Lippincott: Philadelphia 1978; pp. 125-9.

[16] Lui NL, Inman RD. Atlanto-axial subluxation as the initial manifestation of spondyloarthritis. Joint Bone Spine 2011; 78(4); 415-7.

[17] Matucci-Cerinic M, Furst D, Fiorentino D. Skin Manifestations in Rheumatic Disease. 2014 ed. USA: Springer; 2014.

[18] Khan MA, Khan MK. Diagnostic value of HLA-B27 testing ankylosing spondylitis and Reiter's syndrome. Ann Intern Med 1982; 96(1); 70-6.

[19] Leirisalo M, Skylv G, Kousa M, et al. Followup study on patients with Reiter's disease and reactive arthritis, with special reference to HLA-B27. Arthritis Rheum 1982; 25(3); 249-59.

[20] Sampaio-Barros PD, Conde RA, Donadi EA, et al. Frequency of HLA-B27 and its alleles in patients with Reiter syndrome: comparison with the frequency in other spondyloarthropathies and a healthy control population. Rheumatol Int 2008; 28(5): 483-6.

[21] McClusky OE, Lordon RE, Arnett FC, Jr. HL-A 27 in Reiter's syndrome and psoriatic arthritis: a genetic factor in disease susceptibility and expression. J Rheumatol 1984; 11(5): 571.

[22] Olivieri I, Cantini F, Salvarani C. Diagnostic and classification criteria, clinical and functional assessment, and therapeutic advances for spondyloarthropathies. Curr Opin Rheumatol 1997; 9(4): 284-90

[23] Jeon SW, Jeong JH, Moon SM, Choi SK. Atlantoaxial rotatory fixation in adults patient. J Korean Neurosurg Soc 2009; 45(4): 246-8.

[24] McGraw RW, Rusch RM. Atlanto-axial arthrodesis. J Bone Joint Surg 1973; 55B: 482-9.

[25] Crook TB, Eynon CA. Traumatic atlantoaxial rotatory subluxation. Emerg Med J 2005; 22(9); 671-2.

[26] Chen J, Liu C, Lin J. Methotrexate for ankylosing spondylitis Cochrane Database Syst Rev 2006; 4; CD004524.

[27] Haibel H, Specker C. Disease-modifying anti-rheumatic drugs in rheumatoid arthritis and ankylosing spondylitis. Clin Exp Rheumatol 2009; 27(4 Suppl 55); S159-63.

[28] Dougados M, Combe B, Braun J, et al. A randomised, multicentre, double-blind, placebo-controlled trial of etanercept in adults with refractory heel enthesitis in spondyloarthritis: the HEEL trial. Ann Rheum Dis2010; 69(8); 1430-5.

[29] Moore KR, Frank EH. Traumatic atlantoaxial rotatory subluxation and dislocation. Spine (Phila Pa 1976) 1995; 20(17); 1928-30.

[30] Shen FH, Samartzis D, Jenis LG, An HS. Rheumatoid arthritis: evaluation and surgical management of the cervical spine. Spine J2004; 4(6); 689-700.

[31] Weisskopf M, Naeve D, Ruf M, Harms J, Jeszenszky D. Therapeutic options and results following fixed atlantoaxial rotatory dislocations. Eur Spine J 2005; 14(1); 61-8.

[32] Kransdorf MJ, Wehrle PA, Moser RP, Jr. Atlantoaxial subluxation in Reiter's syndrome. A report of three cases and review of the literature. Spine (Phila Pa 1976) 1988; 13(1); 12-4. 